\title{
Spatial and temporal dispersal patterns of Diachasmimorpha longicaudata (Hymenoptera: Braconidae) reared on Ceratitis capitata and Anastrepha fraterculus (Diptera: Tephritidae)
}

\author{
Maria Gisely Camargos $^{\mathrm{a}, *}$, Clarice Diniz Alvarenga ${ }^{\mathrm{a}}$, Ronaldo Reis Júnior ${ }^{\mathrm{b}}$, \\ Julio Marcos Melges Walder ${ }^{\mathrm{c}}$, Jefferson Castro Novais ${ }^{\mathrm{a}}$ \\ a State University of Montes Claros, Department of Agricultural Sciences, Reinaldo Viana Street, 2630, 39440-000 Janaúba, MG, Brazil \\ ${ }^{\mathrm{b}}$ State University of Montes Claros, Department of Biology, University Campus Professor Darcy Ribeiro, CP: 126, 39401-089 Montes Claros, MG, Brazil \\ ${ }^{\mathrm{c}}$ Laboratory of Food Irradiation and Radioentomology, State University of São Paulo/CENA, Centenário Avenue, 303, 13416-000 Piracicaba, SP, Brazil
}

A R T I C L E I N F O

\section{Keywords:}

Fruit flies

Parasitism

Psidium guajava

Sentinel hosts

Survival

\begin{abstract}
A B S T R A C T
The dispersal and parasitism abilities of Diachasmimorpha longicaudata, reared on the larval hosts Ceratitis capitata and Anastrepha fraterculus, were evaluated in a guava orchard. Eleven releases of approximately 3000 parasitoids were conducted in a 15-ha orchard and wasp dispersal was monitored from 6 to $272 \mathrm{~m}$ away from a central release point. At each monitoring point, larvae of $C$. capitata and A. fraterculus were offered as hosts for the parasitoids. In five releases, parasitoids were offered only one host species, and in six releases, they were given a choice. In total, 10,351 parasitoids were recovered from these hosts, all of which were $D$. longicaudata. Both parasitoid strains dispersed in all directions, but showed a slight bias towards the east. Both strains of the parasitoid survived and parasitized larvae of $A$. fraterculus and $C$. capitata for up to 15 days after release, with maximum activity during the first 7 days, but more individuals of the Anastrepha strain were recovered after 15 days. Although the highest rates of parasitism by both wasp strains occurred close to the release point, the Anastrepha strain parasitized more hosts at greater distances from the release point, whereas the Ceratitis strain parasitized more hosts close to release points. Releases of the Anastrepha strain of $D$. longicaudata are therefore recommended, as this strain yields high rates of parasitism further away from release points and appears to survive longer in the field.
\end{abstract}

\section{Introduction}

The evaluation of parasitoids dispersal capacity is an important tool in determining the number of release points and consequently in the development of methodologies that facilitate the efficiency of this group of insects in the field, especially in inundative releases (Zachrisson and Parra, 1998). The search process performed by the parasitoid in the field is divided into four phases: the location of the host habitat, the host location itself, the acceptance of the host and parasitism (Vinson, 1985). Knowledge on the distance and dispersal time of the Diachasmimorpha longicaudata (Ashmead) (Hymenoptera: Braconidae) fruit fly parasitoid reared in different hosts is essential for the behavior of the parasitoids to be understood following their release in the field. Variation in the distance from the release site may result in variability in the rate of parasitism in a given crop, because of the biological characteristics of the parasitoid, such as its ability to fly and/ or inherent characteristics of the crop itself. Therefore, these variations depend on both the type and development of the cultures studied and the biological characteristics of the parasitoid chosen (Bueno et al., 2012).

The species of fruit fly in which $D$. longicaudata is reared is one factor that can determine the efficiency of the parasitoid, as its performance can be affected by the quality of the host (Ovruski et al., 2011). Both Ceratitis capitata (Wiedemann) and Anastrepha fraterculus (Wiedemann) are suitable hosts for the development of $D$. longicaudata (Ovruski et al., 2003,2007). However, more females can be obtained using the larger A. fraterculus larvae as hosts (Ovruski et al., 2011). Laboratory tests have shown that parasitoids produced in $A$. fraterculus larvae are significantly larger with a greater number of insects capable of flying $(\sim 90 \%)$ than those produced in C. capitata (Morelli-deAndrade, 2013). However, other factors can affect parasitoid performance in the field, as each parasitoid lineage may vary in intrinsic capacity to forage in different agro ecosystems (Pratissoli et al., 2002).

Through learning, many parasitoids can increase their searching

\footnotetext{
* Corresponding author.

E-mail address: mariagisely@hotmail.com (M.G. Camargos).
} 
efficiency in particular environmental conditions and may even alter their preference for a certain host species (Corbet, 1985; Nurindah et al., 1999). Thus, wasps can modify their behavior in response to stimuli perceived in either the juvenile or adult environment, a phenomenon known as associative learning or $\alpha$-conditioning (Vinson, 1998).

D. longicaudata females use chemical signals emanating from the host and its habitat when foraging (Segura et al., 2012). Therefore, the nature of the habitat, the host species in which the parasitoid was reared, the species of fruit fly to be controlled, and the dispersal behavior of female wasps must all be considered in designing inundative release programs.

The present study was carried out to evaluate, under field conditions, whether breeding the parasitoid $D$. longicaudata on host larvae of different fruit fly species influences its dispersal capacity and parasitism of the same host larvae when released in a guava orchard under semiarid conditions.

\section{Materials and methods}

Field experiments were carried out in a 15 ha irrigated plantation of guava, Psidium guajava L., cv Paluma, in Jaíba, Minas Gerais, Brazil (15 $14^{\circ} 03.7^{\prime \prime} \mathrm{S}$ and $\left.43^{\circ} 56^{\prime} 54.0^{\prime \prime} \mathrm{W}\right)$, from March 2014 to May 2015. The local climate is considered tropical semiarid (Koppen classification) and is characterized by dry winters. The average temperature in the region is $24.5^{\circ} \mathrm{C}$, with a mean elevation of $500 \mathrm{~m}$ and an average annual precipitation of $925 \mathrm{~mm}$ (CLIMA TEMPO, 2017). Throughout the study period, fruit was not present in the orchard, no pruning was conducted, but irrigation was maintained, and no pesticides were sprayed. The climatic information was obtained on the conventional meteorological station of the National Institute of Meteorology (INMET, 2015), at about $20 \mathrm{~km}$ from the orchard.

D. longicaudata individuals were reared on either third instar larvae of $C$. capitata (this strain had been maintained on the same host for about 10 years) or $A$. fraterculus (maintained on this host for 12 generations at start of experiment). Hereafter, these are referred to as the Ceratitis and Anastrepha strains, respectively. Adult parasitoids were kept at $25^{\circ} \mathrm{C} \pm 1{ }^{\circ} \mathrm{C} ; 60 \pm 10 \% \mathrm{RH}$, and 12:12 (L:D) h photoperiod in wood-framed, mesh-covered cages $(0.4 \times 0.4 \times 0.4 \mathrm{~m}), 1000$ pairs per cage. Parasitoids were provided daily with honey and water.

Starting from the center of the experimental area in the guava orchard (the release point), points were marked equidistant along transects radiating in eight cardinal directions (N, NE, E, SE, S, SW, W, and NW) to describe sixteen circles, with average distances of $6,17.5$, $30.5,46.5,61,75.5,90,104,119,133,148,162,177,191,206$, and $220 \mathrm{~m}$, and one point in each direction or eight points per circle, except for the first and last circles, which comprised only four points, totaling 124 points (Fig. 1).

Approximately 3000 parasitoids (1:3, males:females) were released in the center of a guava orchard at 3-week intervals, in each release, totaling 11 releases. In five releases, the parasitoid had no choice of host (with parasitism units containing only one of the host species), and in six releases the parasitoid chose the host species (two parasitism units, each with one host) (Fig. 2). The parasitoids were 5-7-days-old and within their period of maximum fecundity (López et al., 2009).

Dispersal and parasitism by $D$. longicaudata were evaluated in the field using sentinel traps containing about 20 third-instar larvae of $C$. capitata and/or A. fraterculus and an artificial food source wrapped in voile fabric (Fig. 2). When wasps disperse from a central release point they become distributed over a progressively greater area and become more difficult to recapture, i.e., there is an area dilution effect. According to Mills et al. (2006), the use of attractive traps reduces the area dilution effect, thus facilitating wasp access to the most distant points in the outer circles of the dispersal area. Before each parasitoid release, a sentinel trap was placed at each sampling point in the orchard.

Sentinel traps were placed at sampling points 24, 48, 168 (day 7),

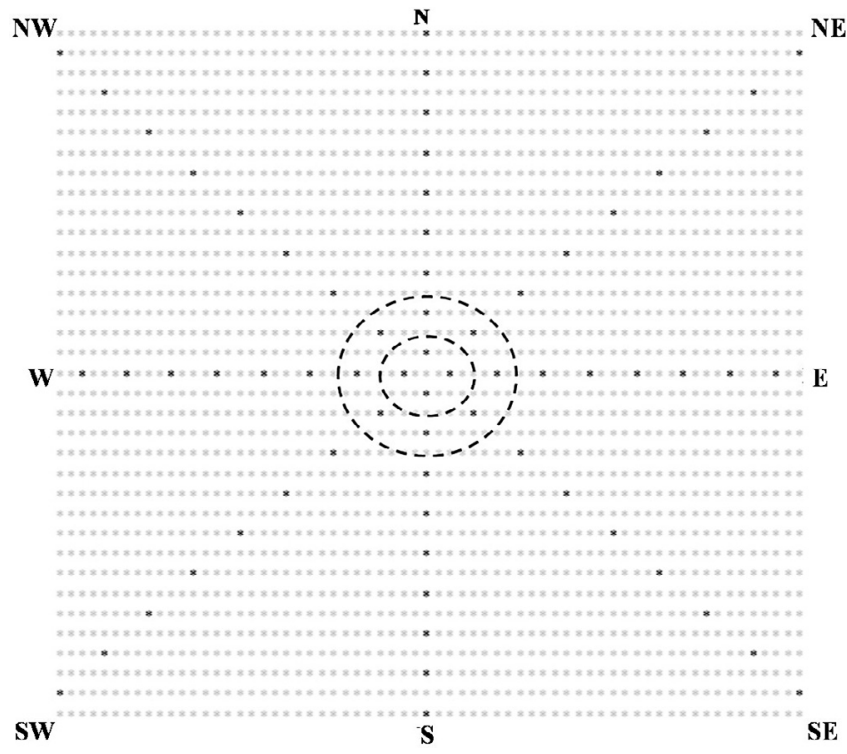

Fig. 1. Distribution of points used to evaluate the dispersal of Diachasmimorpha longicaudata wasps released in a guava orchard. Only two of eight circles are depicted for illustration purposes.

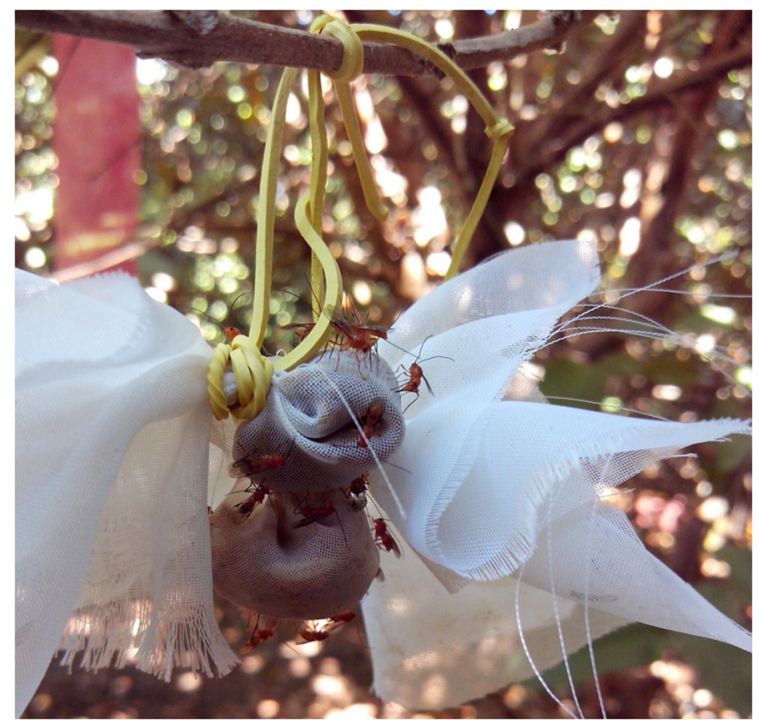

Fig. 2. Sentinel traps for Diachasmimorpha longicaudata, each containing about 20 third-instar larvae of $C$. capitata and/or A. fraterculus and an artificial food source wrapped in voile fabric arranged in guava plants in Jaíba, Minas Gerais, Brazil.

and $360 \mathrm{~h}$ (day 15) after each parasitoid release, and left in the orchard for $24 \mathrm{~h}$, so that parasitism would not be cumulative. Once removed from the field, sentinel larvae were transferred to glass containers containing a moist vermiculite layer, covered with voile fabric, and held in the laboratory for pupation. All emerged adult wasps were preserved in $70 \%$ ethanol for subsequent identification.

Percentage parasitism (P) in each sentinel trap was calculated as the number of adult parasitoids emerged divided by total number of emerged parasitoids and fruit flies, times 100 . The sex ratio of parasitoids (SR) was calculated as the proportion female, and percentage host mortality (M) as the number of host larvae - number of emerged adults ( $D$. longicaudata and fruit flies), times 100 , divided by the total number of larvae.

The data were analyzed with generalized linear models of mixed 
effects using the GLMER function in the lme4 package in the R Statistical System (Bates et al., 2015, R Core and Team, 2015). Parasitoid strain, host species, radial distance from release point, time after release, host choice, direction of dispersal, climatic variables, and all double interactions between these variables were considered as factors in the models.

Two independent models were created, one without consideration of the time elapsed from parasitoid release, and one without consideration of the dispersal radius. Thus, one model corrected for spatial pseudorepetition and the other corrected for temporal pseudorepetition. From the complete model, the best model was generated using stepwise elimination of non-significant factors and then selecting that with the lowest Akaike Information Criterion (AIC) (Burnham and Anderson, 2004). The MuMIn package was used to select models (Bartoń, 2015). The effects of climatic variables precipitation, temperature, and relative humidity were tested for quasibinomial distribution with respect to percent parasitism and mortality of host larvae. To estimate the proportion of hosts parasitized, we calculated the radius and the time required for $90 \%$ of host larvae to be parasitized in the sentinel traps and used the following general equation: $\mathrm{x}=\exp$ $([\log (\mathrm{p} /[1-\mathrm{p}])-\mathrm{a}] / \mathrm{b})$, where $\mathrm{a}$ and $\mathrm{b}$ are the parameters estimated in the two previous models, $\mathrm{x}$ is the variable of interest (time or radius), and $p$ is the value of interest (0.9).

The average dispersal distance (DM) and dispersal area $\left(S^{2}\right)$ of parasitoids in each collection of samples were estimated using the model proposed by Dobzhansky and Wright $(1943,1947)$ as described below:

$$
\begin{aligned}
S^{2}= & {\left[\sum\left(r^{3} \times \mathrm{i} / \mathrm{a}\right) / \sum(\mathrm{r} \times \mathrm{i} / \mathrm{a})+\mathrm{C} / 2 \pi\right] ; D M=\left[\sum\left(\mathrm{r}^{2} \times \mathrm{i} / \mathrm{a}\right)\right.} \\
& \left./ \sum(\mathrm{r} \times \mathrm{i})+\mathrm{C} / 2 \pi\right] ;
\end{aligned}
$$

where: $S^{2}=$ dispersion area $\left(\mathrm{m}^{2}\right)$ during the experimental period; $\mathrm{DM}=$ average dispersion distance $(\mathrm{m})$ of parasitoids during the experimental period; $r=$ distance $(\mathrm{m})$ from the center to the traps (parasitism units); $a=$ the number of traps per circle (four for the first circle and eight for the other circles, at the distances [radius] studied); $\mathrm{C}=$ average parasitoids obtained in the central circle; $\mathrm{i}=$ parasitism rate (parasitism units) in each circle.

The dispersal direction of $D$. longicaudata strains was analyzed by constructing four models, one for each combination of host and strain, without considering whether there was a choice of hosts, to test dispersal directions. Generalized linear model (GLM) was used with a quasibinomial distribution and then a contrast analysis was performed between the directions (Crawley, 2007). To confirm the dispersal direction, the Watson test was used to verify the adjustment of the circular data in relation to the von Mises distribution, using the Circular and CircStat packages (Jammalamadaka and Sengupta, 2001).

\section{Results}

The highest numbers of $D$. longicaudata were recovered after releases of the Anastrepha strain and emergence of parasitoids from $A$.

Table 1

Numbers of parasitoids recovered from sentinel traps and their sex ratios after 11 releases of two strains of Diachasmimorpha longicaudata reared on different host species (Anastrepha strain and Ceratitis strain) in a guava orchard in Jaíba, Minas Gerais, Brazil.

\begin{tabular}{lllllll}
\hline \multirow{2}{*}{ Host } & Sex & \multicolumn{2}{l}{ Anastrepha strain } & \multicolumn{2}{l}{ Ceratitis strain } & \multirow{2}{*}{ Total } \\
\cline { 3 - 6 } & & Number & Sex ratio & Number & Sex ratio \\
& & & & & \\
\cline { 3 - 6 } Anastrepha & Male & 453 & 0.34 & 57 & 0.28 & 510 \\
fraterculus & Female & 237 & & 22 & & 259 \\
Ceratitis capitata & Male & 4053 & 0.30 & 2483 & 0.34 & 6536 \\
& Female & 1761 & & 1285 & & 3046 \\
Total & & 6504 & 0.31 & 3847 & 0.34 & 10,351 \\
\hline
\end{tabular}

Table 2

Analysis of deviance of the total mortality of Anastrepha fraterculus and Ceratitis capitata parasitized by Diachasmimorpha longicaudata in sentinel traps after the wasps were released in a guava orchard.

\begin{tabular}{llc}
\hline AIC $=15249.0$ & & \\
\hline Source of variation & Chisq & $\mathrm{P}$ \\
\hline Choice & 6.1191 & 0.0134 \\
Host & 25951.9929 & $<0.0001$ \\
Strain & 0.0618 & 0.8037 \\
Choice:Host & 5.6870 & 0.0171 \\
Host:Strain & 99.3987 & $<0.0001$ \\
\hline
\end{tabular}

fraterculus larvae was less than from $C$. capitata larvae (Table 1). The mortality of $A$. fraterculus larvae caused by the two parasitoid strains were statistically different (Table 2), and their mortality also differed between host choice / no choice situations (Fig. 3). In releases where the parasitoids could choose hosts, the mortality of $A$. fraterculus larvae was the highest, exceeding 70\%, especially when the Anastrepha strain was released. The mortality of $C$. capitata larvae did not differ between choice and no choice situations.

There was no significant difference in percentage parasitism between host species in traps $(\mathrm{P}<0.05$, Table 3 ), independent of the strain and host. The highest rates of parasitism were observed in larvae up to the 10 th radius $(133 \mathrm{~m})$. Both strains of parasitoids reached host larvae at the radius furthest from the release point, a mean distance of $220 \mathrm{~m}$ (Fig. 4).

There was no significant difference in percent parasitism among the parasitoid strains at any distance from the central release point, but $C$. capitata was parasitized more than $A$. fraterculus. The Anastrepha strain obtained higher percent parasitism of this host at more distant points compared to $A$. fraterculus (Fig. 4). The percentage of parasitism varied significantly with distance from the release point, decreasing with increasing distance from the release point. Parasitism by both parasitoid strains decreased along the radius at the same speed (Table 4).

Percentage parasitism of both host species by both $D$. longicaudata strains was higher in the first $48 \mathrm{~h}$ in than at later times (Fig. 5). Both parasitoid strains remained active for up to 15 days $(360 \mathrm{~h})$ after release, but only 44 specimens were recovered at 15 days. Of these, $79 \%$ were the Anastrepha strain recovered from $C$. capitata larvae, whereas $18 \%$ of these were recovered from $A$. fraterculus larvae, with only one Ceratitis strain parasitoid recovered from $C$. capitata larvae. The highest rates of parasitism were obtained with the Anastrepha strain the first hours after parasitoid release. Independent of strain, $C$. capitata suffered the highest rates of parasitism for longer period after release, and larvae of both hosts were parasitized for a longer period by the Anastrepha strain.

Ninety percent of parasitized host larvae were parasitized at greater distances when the Anastrepha strain was released and females of this strain obtained $90 \%$ of their parasitism of $C$. capitata larvae within $43.44 \mathrm{~m}$ from the release point, and $90 \%$ of their parasitism of $A$. fraterculus larvae within $22.20 \mathrm{~m}$ from the release point. (Table 5). Further out, percentage parasitism decreased with distance (Fig. 4). Most A. fraterculus larvae (90\%) were parasitized by both parasitoid strains at locations closer to the release site. Similarly, the period of effective parasitoid activity after release was lower when the Ceratitis strain parasitized $A$. fraterculus larvae. In one hour, Ceratitis females strain parasitized $90 \%$ of these larvae (of all those parasitized) in the first meters of dispersal (Table 5). However, it took $60 \mathrm{~h}$ post-release for the same strain to achieve $90 \%$ percentage parasitism of $C$. capitata larvae (Fig. 5). The capacity of Ceratitis females to parasitize A. fraterculus was reduced one hour post-release, whereas for $C$. capitata larvae, it was not significantly reduced until $60 \mathrm{~h}$ after release. Likewise, females of the Anastrepha strain took less time to parasitize $90 \%$ of $A$. fraterculus larvae 
than they did $90 \%$ of the $C$. capitata larvae.

The sex ratio of collected parasitoids was low, independent of host or parasitoid strain, with males outnumbering females (Table 1). The best model for sex ratio showed that differences were only significant between hosts (AIC $=3098.8$, Chisq $=5.8466, \quad \mathrm{p}=0.01561$ ). Although male-biased, the sex ratio was higher in parasitoids recovered from A. fraterculus than in those recovered from $C$. capitata $[31.51 \% \mathrm{SE}$ $(+6.97,-6.23)$ vs. $27.79 \%(+6.56,-5.73)$, respectively], independent of strain.

Based on the model of Dobzhansky and Wright (1943, 1947), D. longicaudata reached an average maximum dispersal distance of $173.19 \mathrm{~m}$ and a dispersal area of $34,067.17 \mathrm{~m}^{2} 7$ days after release. The largest distances and areas of dispersal were achieved by females of the Ceratitis strain when they parasitized C. capitata larvae (Table 6). Females of the Anastrepha strain dispersed more rapidly, reaching larvae of $A$. fraterculus at a mean distance of $114 \mathrm{~m}$ and a dispersion area of $17,343.68 \mathrm{~m}^{2}, 24 \mathrm{~h}$ after release. The mean distance and dispersion area were not calculated for $360 \mathrm{~h}$ ( 15 days) after release because of the low number of parasitoids recovered at this time.

The contrast analysis assessing the dispersal directions of $D$. longicaudata (Table 7) showed that east was the only direction that did not resemble any other, for any strain or host combination. Similarly, by circular analysis, we observed a tendency of dispersal towards the east in all situations (Fig. 6).

Climatic variables were tested with a quasibinomial distribution for the rate of parasitism and the mortality of host larvae, but no climatic variables significantly influenced parasitism or host mortality ( $\mathrm{P}>0.05$ in all cases).

\section{Discussion}

We did not recover any native parasitoids during this study. Natural parasitism of tephritid flies in semi-arid regions is generally low, probably due to adverse climatic conditions (Alvarenga et al., 2005; Araujo and Zucchi, 2002), as previously observed in irrigated coffee plantations in this region (Camargos et al., 2016). However, the abiotic factors: precipitation, temperature, and relative humidity did not influence the parasitism behavior of $D$. longicaudata after release. Sivinski et al. (1998) inferred that higher temperatures favor $D$. longicaudata, but there were no major weather changes in the region during the study period, which is known for high average temperatures and low relative humidity. However, because the orchard was irrigated, this produced a microclimate with high relative humidity.

Although emergence of wasps from $A$. fraterculus was low, mortality of larvae was high. A high intensity of parasitism can reduce $D$. longicaudata emergence from hosts, while at the same time inducing larvae mortality. Superparasitism is common in this species (Altafini et al., 2013; González et al., 2007; Meirelles et al., 2013; Montoya et al., 2012) and was likely significant after $24 \mathrm{~h}$ of host exposure. Although the number of oviposition scars was not recorded, wasps to parasitized up to $90 \%$ of $A$. fraterculus larvae in sentinel traps at the points closest to the release point much faster than they did $C$. capitata larvae, leading to high mortality of the former, and suggesting that superparasitism occurred in these larger larvae. Larval mortality did not differ between $D$. longicaudata strains, but the Anastrepha strain caused high mortality of $A$. fraterculus larvae when provided with a choice of hosts. A Similarly, Sá (2015) observed higher mortality of larvae (A. fraterculus and C. capitata) successfully parasitized by the Anastrepha strain compared

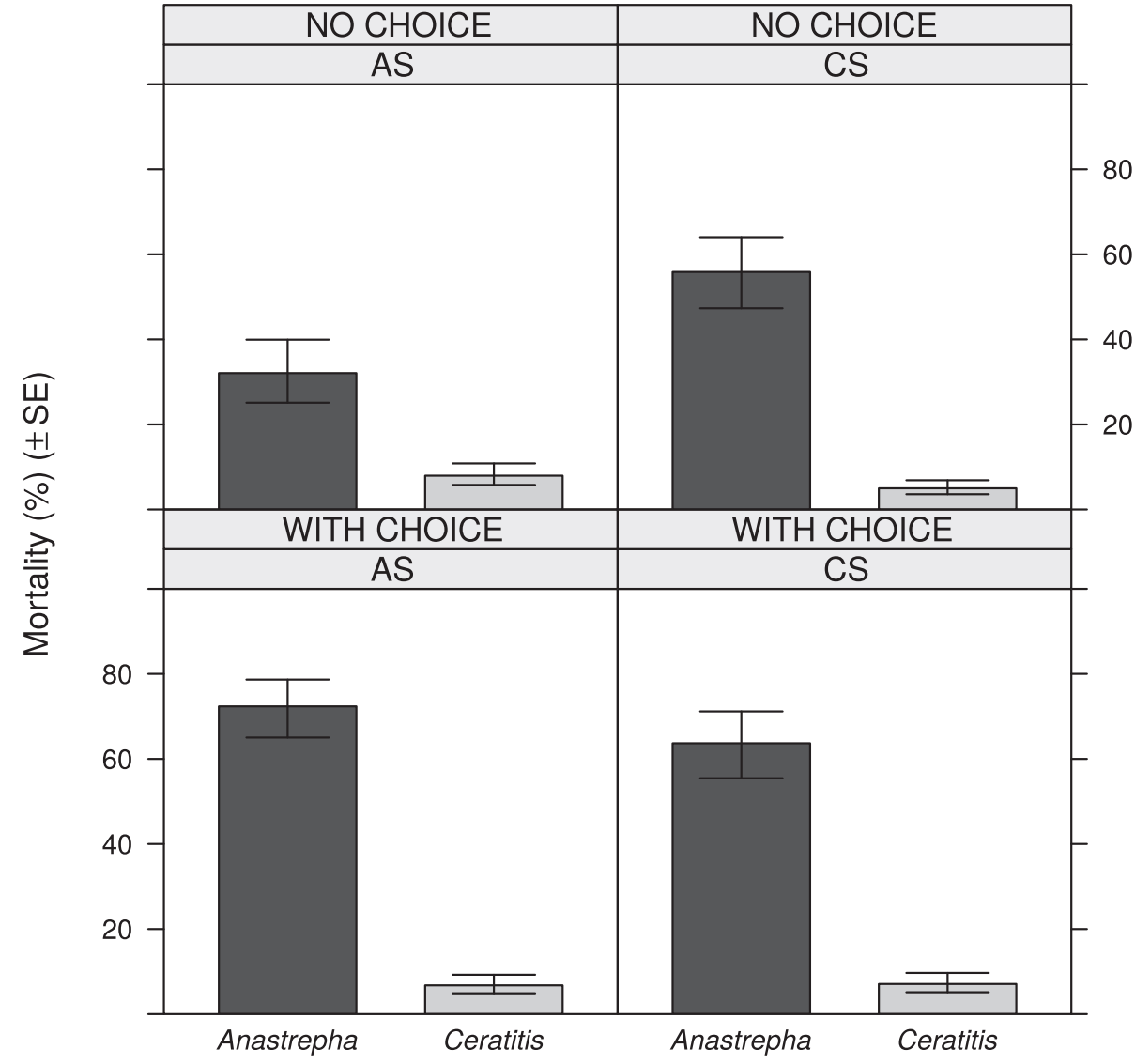

Fig. 3. Mean ( $\pm \mathrm{SE}$ ) mortality of Anastrepha fraterculus and Ceratitis capitata larvae following releases of two Diachasmimorpha longicaudata strains in a guava orchard. AS = Anastrepha strain, CS = Ceratitis strain, WITH $=$ with host choice, WITHOUT $=$ without host choice. Analysis of deviance of generalized linear mixed-effect models with quasibinomial distribution $(\mathrm{P}<0.05$, AIC $=15249.0)$. 
Table 3

Analysis of deviance of percentage parasitism of Anastrepha fraterculus and Ceratitis capitata larvae by two Diachasmimorpha longicaudata strains.

Spatial model - AIC $=12908.7$

\begin{tabular}{llc}
\hline Source of variation & Chisq & $\mathrm{P}$ \\
\hline Host & 403.4961 & $<0.0001$ \\
Strain & 0.5923 & 0.4415 \\
Log (ray) & 166.4011 & $<0.0001$ \\
Host:Strain & 69.9497 & $<0.0001$ \\
Temporal model - AIC $=3772.9$ & & \\
Host & Chisq & $\mathrm{P}$ \\
Strain & 636.0078 & $<0.0001$ \\
Log (time) & 1.4246 & 0.2326 \\
Host:Strain & 226.2637 & $<0.0001$ \\
Host:log (time) & 76.7977 & $<0.0001$ \\
\hline
\end{tabular}

to larvae that were not parasitized, again when the parasitoid had a choice of hosts.

Percentage parasitism did not differ for either wasp strain whether there was a choice of hosts or not, so it seems likely that $D$. longicaudata females have no preference for either host. Females are not able to discriminate between volatiles produced by $C$. capitata versus $A$. fraterculus larvae in infested guavas (Silva et al., 2007), and choice tests have found no significant preference for either host species (Ovruski et al., 2011). However, when no choice was provided, D. longicaudata parasitized more of the host in which it was reared (López et al., 2009; Ovruski et al., 2011; Sá, 2015). Parasitism was highest closest to the point of parasitoid release, and decreased with increasing distance. This has been observed in other dispersal studies, because as distance increases, search area increases, and natural mortality occurs during the course of dispersion (Geremias and Parra, 2014). The same phenomenon was observed in coffee plantations, using $C$. capitata larvae as sentinel hosts (Camargos et al., 2016). Avila et al. (2013) reported that the solitary endoparasitoid Cotesia urabae Austin and Allen (Hymenoptera: Braconidae) dispersed and parasitized sentinel larvae of the lepidopteran pest Uraba lugens Walker up to $20 \mathrm{~m}$ away from the release point, but parasitism was highest within a radius of five $\mathrm{m}$ from the release tree.

Both strains of the parasitoid parasitized host larvae out to the last radius, an average distance of $220 \mathrm{~m}$ from the point of release. When the host species were compared, C. capitata was the most parasitized, but considering the low number of repetitions and the high mortality of A. fraterculus, parasitism of this host may have been underestimated. The Anastrepha strain of $D$. longicaudata obtained the highest rate of parasitism, and reached C. capitata larvae even at the most distant points. Parasitoids produced in $A$. fraterculus larvae are significantly larger and a greater proportions are capable of flight ( $\sim 90 \%)$ compared to those produced in C. capitata (Morelli-de-Andrade, 2013). This is probably why the Anastrepha strain reached greater distances and achieved higher parasitism than the Ceratitis strain in the present study.

Both strains of parasitoid produced some offspring, but most of those recovered after 15 days were of the Anastrepha strain, which also

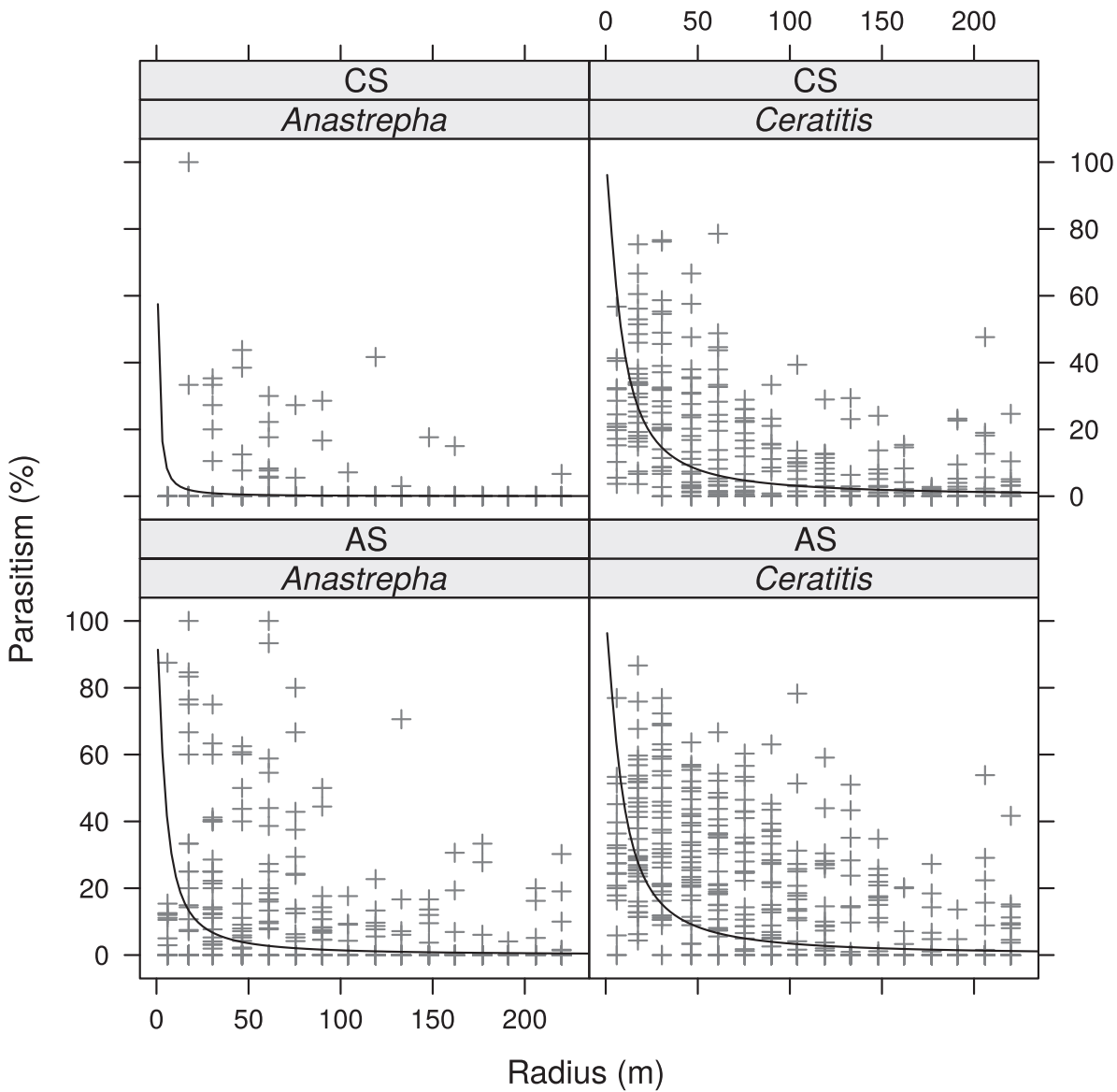

Fig. 4. Percentage parasitism by two strains of Diachasmimorpha longicaudata in sentinel traps containing Anastrepha fraterculus and Ceratitis capitata larvae and arranged at different distances from the parasitoid release point in a guava orchard in Jaíba, Minas Gerais, Brazil. AS = Anastrepha strain, $\mathrm{CS}=$ Ceratitis strain. Analysis of deviance of generalized linear mixed-effect models with quasibinomial distribution $(\mathrm{P}<0.05$, AIC $=12908.7)$. 
Table 4

Parameters used for regressions in the theoretical model of parasitism radius (Fig. 4) of Diachasmimorpha longicaudata strains parasitizing larvae of Anastrepha fraterculus and Ceratitis capitata. AIC $=12908.7$. AS = Anastrepha strain, $\mathrm{CS}=$ Ceratitis strain.

\begin{tabular}{lll}
\hline Effect & Intercept & Coefficient of slope \\
\hline Parasitism (Anastrepha + AS) & 2.02259 & -1.36117 \\
Parasitism (Ceratitis + AS) & 2.93627 & -1.36117 \\
Parasitism (Anastrepha + CS) & -0.03857 & -1.36117 \\
Parasitism (Ceratitis + CS) & 2.88332 & -1.36117 \\
\hline
\end{tabular}

produced the most parasitism in the first hours after release. In releases of D. longicaudata reared on C. capitata, Camargos et al (2016) and Coutinho (2012) recovered parasitoids from C. capitata sentinel larvae for five days after release. These results demonstrated that the Anastrepha strain was able to quickly locate and parasitize hosts, and remained active for longer in the field than the Ceratitis strain. Morelli-deAndrade (2013) observed longer laboratory of both male and female $D$. longicaudata when produced in A. fraterculus compared to $C$. capitata. In our study, some females survived and produced offspring up to 15 days after release, even if they parasitized few hosts in the final days.

In terms of searching behavior, when the host was $C$. capitata, both parasitoids traveled similar distances, but when the host was $A$. fraterculus, the Ceratitis strain travelled a shorter distance than the Anastrepha strain. Some variation in parasitism with distance may have occurred due to differences in flying ability, which might explain why the Anastrepha travelled greater distances and achieved more parasitism. The rearing of $D$. longicaudata in A. fraterculus results in larger insects (Meirelles et al., 2013, Ovruski et al., 2011), which have better flight ability and greater longevity under stress when compared with those reared in C. capitata (Morelli-de-Andrade, 2013). Thus, parasitoids reared in $A$. fraterculus have greater dispersal capacity, with effective parasitism, which could reduce the number of release points required in an augmentation program.

Females of the Ceratitis strain parasitized $90 \%$ of available A. fraterculus larvae in the first $4.8 \mathrm{~m}$ in just $1 \mathrm{~h}$. If most of these females remained closer to the point of release, this could account for the lower percentage parasitism at more distant sites. Notably, females of the Anastrepha strain took only $17 \mathrm{~h}$ to parasitize $90 \%$ of the $A$. fraterculus larvae available in the first $22.2 \mathrm{~m}$, while in $C$. capitata larvae required about $64 \mathrm{~h}$. This may have contributed to more superparasitism of $A$. fraterculus larvae, and thus higher mortality, among those closer to the release point.

As expected, the sex ratio was highest in the A. fraterculus host, regardless of parasitoid strain. However, the sex ratio was low and male-biased (0.34), which may be an artifact of laboratory rearing, or an indication of declining colony vigor.

Although $D$. longicaudata is a solitary endoparasitoid, many several females could be found attacking the same sentinel trap soon after release. Faced with competition from other females, these could exhibit changes in sexual allocation, and in response, produce more male offspring. Parasitoid females can control the sex of progeny by fertilizing eggs or not, and may alter sex ratio in response to changes in their environment (Godfray, 1994). A similar result was obtained in a laboratory study by Alvarenga et al. (2016) who observed that isolated

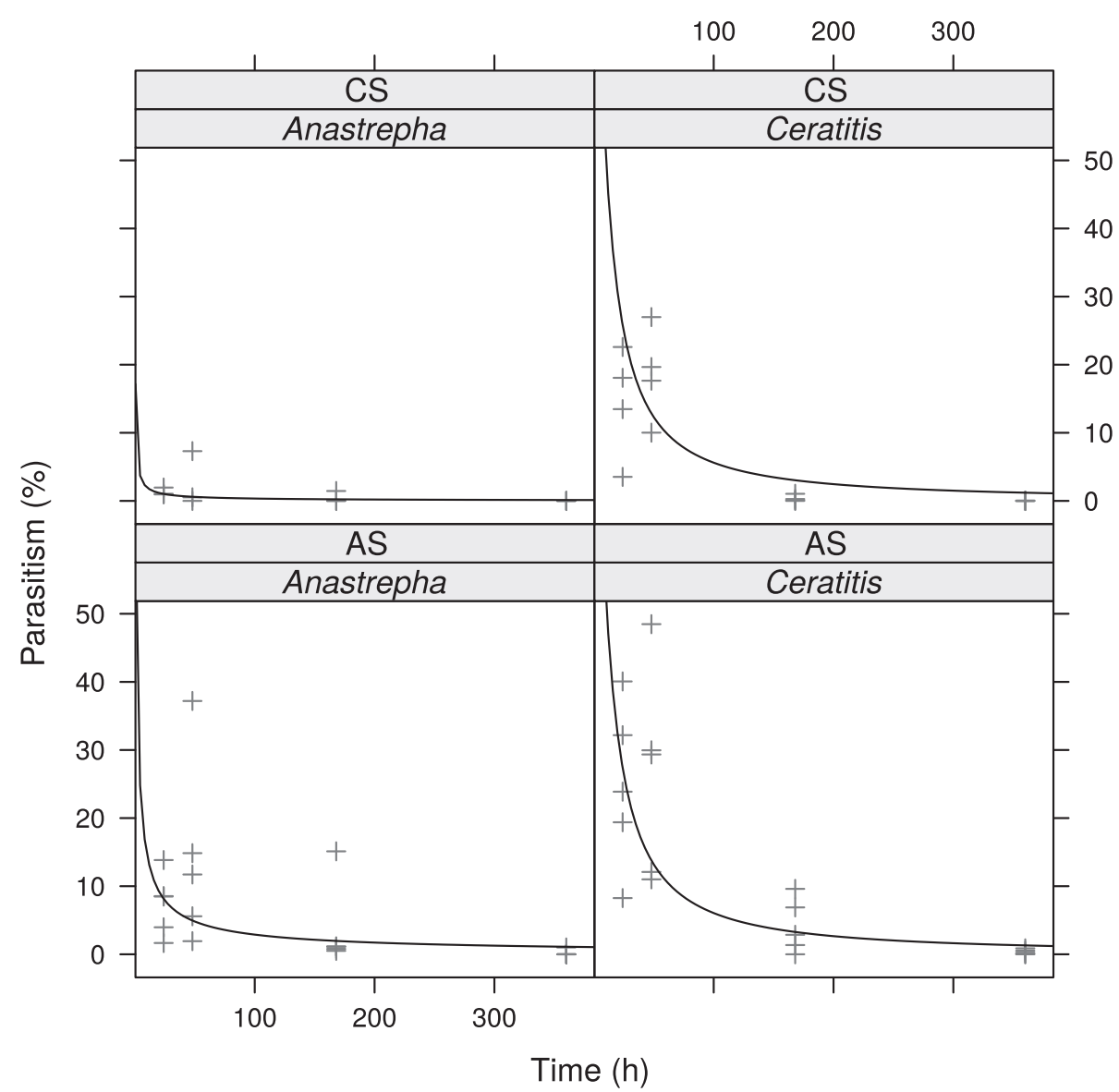

Fig. 5. Percentage parasitism of Anastrepha fraterculus and Ceratitis capitata larvae 24, 48, 168, and $360 \mathrm{~h}$ after release of two strains of Diachasmimorpha longicaudata in a guava orchard in Jaíba, Minas Gerais, Brazil. AS = Anastrepha strain, $\mathrm{CS}=$ Ceratitis strain. Analysis of deviance of generalized linear mixed-effect models with quasibinomial distribution $(\mathrm{p}<0.05$, AIC $=3772.9)$. 
Table 5

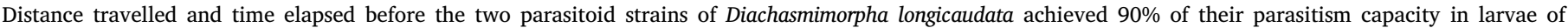

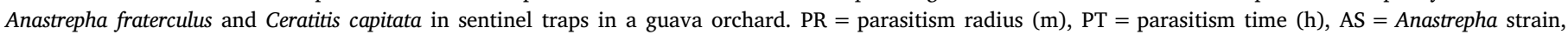
$\mathrm{CS}=$ Ceratitis strain.

\begin{tabular}{|c|c|c|c|c|}
\hline \multirow[t]{2}{*}{ Spatial model AIC = 12908.7} & \multicolumn{4}{|c|}{ Distance travelled (m) } \\
\hline & Anastrepha + AS & Anastrepha + CS & Ceratitis + AS & Ceratitis + CS \\
\hline PR $90 \%$ & 22.20101 & 4.883595 & 43.44014 & 41.78275 \\
\hline Temporal model AIC $=3772.9$ & Time elapsed (h) & & & \\
\hline PT 90\% & 17.86445 & 1.083487 & 64.38836 & 60.32025 \\
\hline
\end{tabular}

${ }^{*} \mathrm{P}<0.05$.

Table 6

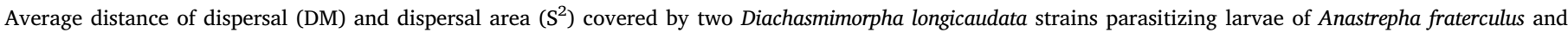

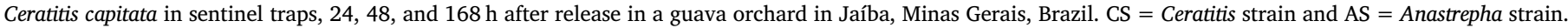

\begin{tabular}{|c|c|c|c|c|c|c|c|c|}
\hline \multirow[t]{2}{*}{ Release Date } & \multirow[t]{2}{*}{ Strain } & \multirow[t]{2}{*}{ Host } & \multicolumn{2}{|l|}{$24 \mathrm{~h}$} & \multicolumn{2}{|l|}{$48 \mathrm{~h}$} & \multicolumn{2}{|l|}{$168 \mathrm{~h}$} \\
\hline & & & $\mathrm{DM}(\mathrm{m})$ & $\mathrm{S}^{2}\left(\mathrm{~m}^{2}\right)$ & $\mathrm{DM}(\mathrm{m})$ & $\mathrm{S}^{2}\left(\mathrm{~m}^{2}\right)$ & $\mathrm{DM}(\mathrm{m})$ & $\mathrm{S}^{2}\left(\mathrm{~m}^{2}\right)$ \\
\hline $26 / 03 / 2014$ & CS & C. capitata & 66.38 & 6827.26 & 80.00 & $10,304.10$ & 45.20 & 3139.09 \\
\hline $15 / 04 / 2014$ & $\mathrm{CS}$ & A. fraterculus & 50.85 & 2728.85 & 71.29 & 6458.86 & 51.97 & 3615.41 \\
\hline $08 / 05 / 2014$ & AS & A. fraterculus & 114.29 & $17,342.68$ & 62.08 & 6445.84 & 66.63 & 5084.20 \\
\hline $02 / 07 / 2014$ & AS & C. capitata & 40.81 & 2765.65 & 37.03 & 2085.84 & 138.68 & $27,368.24$ \\
\hline $26 / 11 / 2014$ & CS & C. capitata & 44.86 & 5639.59 & 112.38 & $19,007.10$ & 104.33 & $10,885.79$ \\
\hline \multirow[t]{2}{*}{$23 / 07 / 2014$} & AS & A. fraterculus & 63.73 & 6070.34 & 89.31 & $13,747.84$ & 105.45 & $14,071.51$ \\
\hline & & C. capitata & 83.86 & 9786.40 & 77.50 & 9019.23 & 51.43 & 3999.10 \\
\hline \multirow[t]{2}{*}{$20 / 08 / 2014$} & AS & A. fraterculus & 40.32 & 2459.64 & 77.90 & 9398.92 & 137.96 & $20,347.16$ \\
\hline & & C. capitata & 64.12 & 7114.41 & 96.20 & $14,912.34$ & 81.74 & 8524.30 \\
\hline \multirow[t]{2}{*}{$29 / 10 / 2014$} & $\mathrm{CS}$ & A. fraterculus & 17.48 & 305.72 & 0.00 & 0.00 & 0.00 & 0.00 \\
\hline & & C. capitata & 37.69 & 4067.86 & 105.21 & 16851.54 & 0.00 & 0.00 \\
\hline \multirow[t]{2}{*}{$14 / 01 / 2015$} & AS & A. fraterculus & 57.73 & 4090.96 & 20.23 & 534.56 & 125.45 & $16,634.64$ \\
\hline & & C. capitata & 94.08 & $12,482.58$ & 72.40 & 6807.86 & 0.00 & 0.00 \\
\hline \multirow[t]{2}{*}{$24 / 03 / 2015$} & $\mathrm{CS}$ & A. fraterculus & 34.62 & 1248.07 & 142.07 & $25,009.01$ & 0.00 & 0.00 \\
\hline & & C. capitata & 93.86 & $12,635.49$ & 102.12 & $14,995.11$ & 173.19 & $34,067.17$ \\
\hline \multirow{2}{*}{$28 / 04 / 2015$} & AS & A. fraterculus & 102.67 & $14,195.95$ & 124.14 & $20,145.75$ & 104.33 & $10,885.79$ \\
\hline & & C. capitata & 98.95 & $12,131.65$ & 113.09 & $15,663.85$ & 104.30 & $13,477.54$ \\
\hline
\end{tabular}

females of both Utetes anastrephae (Viereck) and D. longicaudata produced higher sex ratios (more females) than those paired with a conspecific competitor. This was inferred to be a result of local mate competition (Hamilton, 1967), where females may increase the production of sons to gain fitness through their mating success with the daughters of conspecific females.

After seven days, the Ceratitis strain achieved a higher maximum dispersal distance and dispersion area compared to the Anastrepha strain. In a coffee plantation in the same region, Camargos et al. (2016) reported that Ceratitis strain D. longicaudata parasitized C. capitata

Table 7

Contrasts of dispersal directions for two strains of Diachasmimorpha longicaudata parasitizing Anastrepha fraterculus and Ceratitis capitata larvae in sentinel traps after release in a guava orchard in Jaíba, Minas Gerais, Brazil. (AS = Anastrepha strain, CS = Ceratitis strain).

\begin{tabular}{|c|c|c|c|c|c|c|c|c|c|c|}
\hline \multirow[t]{2}{*}{ AIC } & \multirow[t]{2}{*}{ Strain } & \multirow[t]{2}{*}{ Host } & \multicolumn{8}{|c|}{ Direction } \\
\hline & & & $\mathrm{N}$ & $\mathrm{s}$ & E & W & NW & $\mathrm{NE}$ & SW & SE \\
\hline 2341.4 & AS & A. fraterculus & $\mathrm{a}$ & $\mathrm{b}$ & c & a & B & b & $\mathrm{a}$ & b \\
\hline 8987.7 & AS & C. capitata & a & b & c & $\mathrm{d}$ & E & $\mathrm{f}$ & $\mathrm{g}$ & $\mathrm{h}$ \\
\hline 434.19 & CS & A. fraterculus & a & b & c & $\mathrm{a}$ & A & $\mathrm{e}$ & d & $\mathrm{a}$ \\
\hline 5967.7 & $\mathrm{CS}$ & C. capitata & $\mathrm{a}$ & a & b & $\mathrm{a}$ & A & $\mathrm{a}$ & $\mathrm{a}$ & $\mathrm{a}$ \\
\hline
\end{tabular}

Models were chosen based on the lowest AIC value. Equal letters in the lines represent similar directions $(\mathrm{P}<0.05)$. larvae over a comparably shorter distance $(76.12 \mathrm{~m})$, and reached a lower dispersion area $\left(6,368.57 \mathrm{~m}^{2}\right)$, compared with these releases in a guava orchard. In some cases, parasitoids may respond to the habitat in ways that are independent of the available hosts (Ables et al., 1980; Andow and Prokrym, 1991). Apparently, D. longicaudata disperses more in guava than in coffee, possibly due to factors such as plant architecture and volatiles released by the plants (Segura et al., 2012).

Although both strains of $D$. longicaudata dispersed in all directions in the guava orchard, analysis of the 'rose diagram' revealed a bias towards the east. This easterly bias may reflect characteristics of the crop, such as the row orientation of the trees that might facilitate parasitoid movement in a particular direction. However, there was no correlation between dispersion parameters (DM and $S^{2}$ ) or direction and the climatic conditions of the region, and parasitism behavior was not influenced by any abiotic factors included in the model (precipitation, temperature, or relative humidity), and there were no major weather events during the study period.

The present study leads us to recommend the release of the Anastrepha strain of $D$. longicaudata against fruit flies in guava orchards in any augmentation program to be undertaken. Our results reveal it is more effective in the field than the Ceratitis strain, results in high rates of parasitism over large distances from the release point, and is able to survive and parasitize fruit flies for longer periods in the guava orchard. Based on the average dispersal area of $27,368.24 \mathrm{~m}^{2}$, we recommend that 3000 parasitoids be released for every 2.7 ha of guava orchard. 

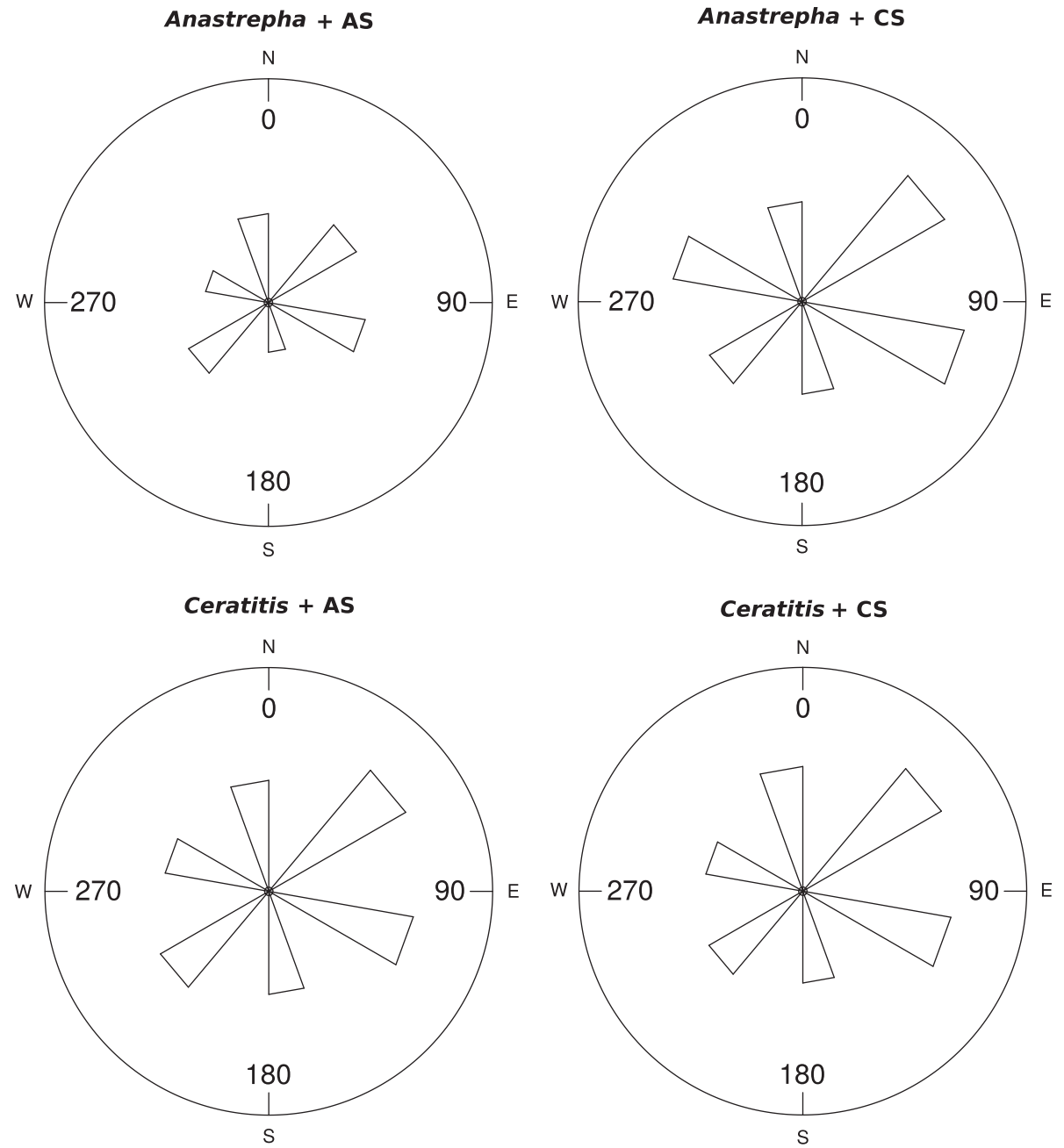

Fig. 6. 'Rose diagram' showing the magnitude of dispersal of two strains of $D$. longicaudata directions in different cardinal directions after release in a guava orchard in Jaíba, Minas Gerais, Brazil. AS = Anastrepha strain, CS = Ceratitis strain.

\section{Acknowledgements}

This work was supported by the Minas Gerais State Foundation for Research Support (FAPEMIG) (Grant Number APQ-00977-09); the Coordination for the Improvement of Higher Level Personnel (CAPES) (granting the PhD scholarship); and Brazilian National Council for Scientific and Technological Development (CNPq) (Grant Number PQ309676/2015-0).

\section{References}

Ables, J.R., McCommas Junior, D.W., Jones, S.L., Morrison, R.K., 1980. Effect of cotton plant size, host egg location, and location of parasite release on parasitism by Trichogramma pretiosum. Southwest Entomol. 5, 261-265.

Altafini, D.L., Redaelli, L.R., Jahnke, S.M., 2013. Superparasitism of Ceratitis capitata and Anastrepha fraterculus (Diptera: Tephritidae) by Diachasmimorpha longicaudata (Hymenoptera: Braconidae). Fla. Entomol. 96, 391-395.

Alvarenga, C.D., Brito, E.S., Lopes, E.N., Silva, M.A., Alves, D.A., Matrangolo, C.R. Zucchi, R.A., 2005. Introduction and recovery of the exotic parasitoid Diachasmimorpha longicaudata (Asmead) (Hymenoptera: Braconidae) in commercial orchards of guava in northern Minas Gerais. Neotrop. Entomol. 34, 133-135.

Alvarenga, C.D., Dias, V., Stuhl, C., Sivinski, J., 2016. Contrasting brood-sex ratio flexibility in two opiine (Hymenoptera: Braconidae) parasitoids of Tephritid (Diptera) fruit flies. J. Insect Behav. 29, 1-12.

Andow, D.A., Prokrym, D.R., 1991. Release density, efficiency and disappearance of Trichogramma nubilale for control of European corn borer. Entomophaga 36, 105-113.

Araujo, E.L., Zucchi, R.A., 2002. Parasitoids (Hymenoptera: Braconidae) of fruit flies (Diptera: Tephritidae) in the region of Mossoró/Assú, Rio Grande do Norte. Arq. Inst. Biol. 69, 65-68.

Avila, G.A., Berndt, L.A., Holwell, G.I., 2013. Dispersal behavior of the parasitic wasp
Cotesia urabae (Hymenoptera: Braconidae): A recently introduced biocontrol agent for the control of Uraba lugens (Lepidoptera: Nolidae) in New Zealand. Biol. Control 66, 166-172.

Bartoń, K. MuMIn: Multi-Model Inference. R package version 1.15.1. Available in: < https://CRAN.R-project.org/package $=$ MuMIn > . (accessed 14.08.15).

Bates, D., Maechler, M., Bolker, B., Walker, S., 2015. Fitting linear mixed-effects models using lme4. J. Stat. Software $67,1-48$.

Bueno, R.C.O.F., Parra, J.R.P., Bueno, F.A., 2012. Trichogramma pretiosum parasitism and dispersal capacity: a basis for developing biological control programs for soybean caterpillars. Bull. Entomol. Res. 102, 1-8.

Burnham, K.P., Anderson, D.R., 2004. Multimodel inference: understanding AIC and BIC in model selection. Soc. Meth. Res. 33, 261-304.

Camargos, M.G., Alvarenga, C.D., Giustolin, T.A., Paranhos, B.A.J., Oliveira, P.C.C., Rabelo, M.M., 2016. Dispersal capacity of fruit fly parasitoid Diachasmimorpha longicaudata (Hymenoptera: Braconidae) in irrigated coffee plantations. Sci. Agric. 73 227-233.

CLIMA TEMPO. Average monthly climate in the last 30 years. Available at: < https:// www.climatempo.com.br/climatologia/3811/jaiba-mg > . (accessed 16.03.17).

Corbet, S.A., 1985. Insect chemosensory responses: a chemical legacy hypothesis. Ecol. Entomol. 10, 143-153.

$\mathrm{R}$ Core Team. $\mathrm{R}$ i386 3.2.2: A language and environment for statistical computing. Vienna: R Foundation for Statistical Computing. Vienna, Austria. Available in: < http://www.R-project.org/ > . (accessed 14.08.15).

Coutinho, C.R., 2012. Dispersion of the parasitoid Diachasmimorpha longicaudata (Ashmead) (Hymenoptera: Braconidae) in irrigated coffee in the semi-arid region of Minas Gerais, Brazil. Dissertation (Master in Plant Production). State University of Montes Claros, Janaúba, pp. 72.

Crawley, M.J., 2007. In: The R Book. Wiley \& Sons, New York, pp. 942p.

Dobzhansky, T., Wright, S., 1943. Genetics of natural populations $\times$ dispersion rates in Drosophila pseudoobscura. Genetics 28, 304-340.

Dobzhansky, T., Wright, S., 1947. Genetics of natural populations. XV. Rate of diffusion of a mutant gene through a population of Drosophila pseudoobscura. Genetics 32, 303-324.

Geremias, L.D., Parra, J.R.P., 2014. Dispersal of Trichogramma galloi in corn for the 
control of Diatraea saccharalis. Biocontrol Sci. Technol. 24, 751-762.

Godfray, H.C.J., 1994. In: Parasitoids Behavioral and Evolutionary Ecology. Princeton University Press, New Jersey, pp. 474p.

González, P.I., Motoya, P., Lachaud-Perez, G., Cancino, J., Liedo, P., 2007. Superparasitism in mass reared Diachasmimorpha longicaudata (Ashmead) (Hymenoptera: Braconidae), a parasitoid of fruit flies (Diptera: Tephritidae). Biol. Control 40, 320-326.

Hamilton, W.D., 1967. Extraordinary sex ratios. Science 156, 477-488.

Instituto Nacional De Meteorologia (INMET), 2015. Estação Meteorológica de Observação de Superfície Convencional. Brasília, DF. Available at: < http://www.inmet.gov.br/ portal/index.php?r = estacoes/estacoesConvencionais > . (accessed 09.08.15).

Jammalamadaka, S.R., Sengupta, A., 2001. Topics in circular Statistics. Singapore: World Scientific Publishing. Available at: < https://books.google.com.br/books?hl=pt-BR $\& \mathrm{l} r=\& \mathrm{id}=\mathrm{sKqWMGqQXQkC \& oi}=\mathrm{fnd} \& \mathrm{pg}=\mathrm{PA} 1 \& \mathrm{dq}=\mathrm{JAMMALAMADAKA},+\mathrm{S} .+\mathrm{R}$. $\% 3 \mathrm{~B}+$ SENGUPTA, + A. + Topics + in + circular + Statistics, + World + Scientific, $+2001 \&$ ots $=$ f4I8PrWuhL\&sig $=7 \_$i6P5NglbIjq0mto9dGu_lpEhw\#v $=$onepage\&q\& $\mathrm{f}=$ false $>$. (accessed 17.08.15)

López, O.P., Hénaut, Y., Cancino, J., Lanbim, M., Cruz-López, L., Rojas, J.C., 2009. Is host size an indicator of quality in the mass-reared parasitoid Diachasmimorpha longicaudata (Hymenoptera: Braconidae). Fla. Entomol. 92, 441-449.

Meirelles, R.N., Redaelli, L.R., Ourique, C.B., 2013. Comparative biology of Diachasmimorpha longicaudata (Hymenoptera: Braconidae) reared on Anastrepha fraterculus and Ceratitis capitata (Diptera: Tephritidae). Fla. Entomol. 96, 412-418.

Mills, N.J., Babendreier, D., Loomans, A.J.M., 2006. Methods for monitoring the dispersal of natural enemies from point source releases associated with augmentative biological control. In: Bigler, F., Babendreier, D., Kuhlmann, U. (Eds.), Environmental Impact of Invertebrates for Biological Control of Arthropods: Methods and Risk Assessment. CAB International, Wallingford, UK, pp. 114-131.

Montoya, P., Pérez-Lachaud, G., Liedo, P., 2012. Superparasitism in the fruit fly parasitoid Diachasmimorpha longicaudata (Hymenoptera: Braconidae) and the implications for mass rearing and augmentative release. Insects 3, 900-911.

Morelli-De-Andrade, R., 2013. Large-scale production of the parasitoid Diachasmimorpha longicaudata (Hymenoptera: Braconidae) in host larvae of Anastrepha fraterculus and Ceratitis capitata (Diptera: Tephritidae) mutant strain tsl-Viena. Thesis (Doctorate in Sciences). Luiz de Queiroz College of Agriculture, University of São Paulo, Piracicaba, pp. 94.

Nurindah, Cribb, B.W., Gordh, G., 1999. Experience acquisition by Trichogramma australicum Girault (Hymenoptera: Trichogrammatidae). Aust. J. Entomol. 38, 115-119.
Ovruski, S.M., Colin, C., Soria, A., Oroño, L., Schliserman, P., 2003. Introducción y establecimiento en laboratorio de Diachasmimorpha tryoni y Diachasmimorpha longicaudata (Hymenoptera: Braconidae, Opiinae) para el control biológico de Ceratitis capitata (Diptera: Tephritidae, Dacinae) en la Argentina. Rev. Soc. Entomol. 62, 49-59.

Ovruski, S.M., Oroño, L.E., Schliserman, P., Nuñez Campero, S., 2007. The effect of four fruit species on the parasitization rate of Anastrepha fraterculus (Diptera: Tephritidae, Trypetinae) by Diachasmimorpha longicaudata (Hymenoptera: Braconidae, Opiinae) under laboratory rearing conditions. Biocontrol Sci. Technol. 17, 1079-1085.

Ovruski, S.M., Bezdjian, L.P., Van Nieuwenhove, G.A., Albornoz-Medina, P., Schliserman, P., 2011. Host Preference by Diachasmimorpha longicaudata (Hymenoptera: Braconidae) Reared on Larvae of Anastrepha fraterculus and Ceratitis capitata (Diptera: Tephritidae). Fla. Entomol. 94, 195-200.

Pratissoli, D., Fornazier, M.J., Holtz, A.M., Gonçalves, J.R., Chioramital, A.B., Zago, H., 2002. Occurrence of Trichogramma pretiosum in commercial areas of tomato, in Espírito Santo, in regions of different altitudes. Hortic Bras. 21, 73-76.

Sá, L.P., 2015. Parasitism of strains of Diachasmimorpha longicaudata (Ashmead), in different species of fruit fly (Diptera: Tephritidae). Dissertation (Master in Plant Production). State University of Montes Claros, Janaúba, pp. 59.

Segura, D.F., Viscarret, M.M., Ovruski, S.M., Cladera, J.L., 2012. Response of the fruit fly parasitoid Diachasmimorpha longicaudata to host and host-habitat volatile cues. Entomol. Exp. Appl. 143, 164-176.

Silva, J.W.P., Bento, J.M.S., Zucchi, R.A., 2007. Olfactory response of three parasitoid species (Hymenoptera: Braconidae) to volatiles of guavas infested or not with fruit fly larvae (Diptera: Tephritidae). Bio. Control 41, 304-311.

Sivinski, J.M., Aluja, M., Holler, T., Eitam, A., 1998. Phenological comparison of two braconid parasitoids of the Caribbean fruit fly (Diptera: Tephritidae). Environ. Entomol. 27, 360-365.

Vinson, S.B., 1985. The behavior of parasitoids. In: Kerkut, G.A., Gilbert, L.I. (Eds.), Comprehensive Insect Physiology Biochemistry and Pharmacology. Pergamon Press, New York, pp. 417-469.

Vinson, S.B., 1998. The general host selection behavior of parasitoid Hymenoptera and a comparison of initial strategies utilized by larvaphagous and oophagous species. Biol. Control 11, 79-96.

Zachrisson, B., Parra, J.R.P., 1998. Capacidade de dispersão de Trichogramma pretiosum Riley, 1879 para o controle de Anticarsia gemmatalis Hubner, 1818 em soja. Sci. Agric 55, 133-137. 